${ }_{20}$ Berg, R.: Biochem. Zeit., 1932, ccliv, 329.

${ }^{20}$ Sbelon, J. H., and Ramage, H.: Biochem. Journ., 1931, xxv, 1608

${ }^{21}$ Fox, H. M., and Ramage, H.: Proc. Roy. Soc., B, 1931, cviii,

Robinson, W. O.: Journ. Ind. and Eng. Chem., 1918, x, 50

Ramage, H.: Nature, 1929, cxxiii, 601.

Idem: South-Eastern Naturalist and Antiquary; Trans. Norwich Conference 1933.

${ }^{25}$ Rámage, H., Sheldon, J. H., and Sheliton, W.: Proc. Roy. Soc., B, 1933, cxiii, 208

26 Wright, N. C., and Papish, J.: Science, 1929, lxix, 78

27 Blumberg, H., and Rask, O. S.: Journ. Nutrition, 1933, vi, 285. Krause, H. D., Orent, E. R., and McCollum, E. V.: Journ. Biol. Chem., 1932, xcvi, 519.

39 Cramer, W.: Lancet, 1932, ii, 174.

${ }^{30}$ Ramage, H., and Sheldon, J. H.: Nature, August 29th, 1931.

${ }^{31}$ Locke, A., Main, E. R., and Rosbash, D. O.: Journ. Clin. Invest., 1932, xi, 527.

32 Elvehjem, C. A., and Hart, E. B.: Journ. Biol. Chem., 1932, $\mathrm{xcy}, 363$.

${ }_{34}^{33}$ Mackay, H.: Arch. Dis. in Child., 1933, viii, 145.

Borst, M., and Königsdorffer, H.: Untersuchungen iuber Porphyrie, Leipzig, 1929.

${ }^{35}$ Zondek, S. G., and Bandmann, M.: Deut. med. Woch., 1933, lix, 91.

${ }^{37}$ Cunningham, I. J.: Biochem. Journ., 1931, xxv, 1267

${ }_{38}$ Mallory, F. B.: Amer. Journ. Path., 1925, i, 117

${ }^{38}$ Herkel, W.: Ziegler's Beit. z. Path. Anat., 1930, lxxxv, 513.

Bertrand, G., and Rosenblatt, M.: C. R. Acad. des Sci., 1932, cxciv, 1405.

"Bishop, W. B. S.: Aust. Journ. Exp. Biol., 1928, v, 125.

Sheldon, J. H., and Ramage, H.: Biochem. Journ., 1933, xxvii, 674.

12 Orent, E. R., and McCollum, E. V.: Journ. Biol. Chem., 1931, xcii, 651.

4. Pryde, J.: Recent Advances in Biochemistry, 1931, third edition.

4 Zbinden, C.: Mém. Soc. Vaud. Sci. Nat., 1930, iii, 233.

4 Editorial, British Medical Journal, 1933, ii, 578.

${ }_{47}^{4}$ Deltzenne, C.: Tíèse de Pairs (Sci.), 1919.

4 Sato, M., and Murata, K.: Journ. Dairy Sci., 1932, xv, 451.

Bertrand, G., and Brandt-Beauzemont, Y.: Ann. de l'Inst. Pasteur, 1931, xlvi, 572.

49 Newell and McCollum: Journ. Nutrition, 1933, vi, 285.

$\checkmark$ Bohn, G., and Drzewina, A.: C. R. Soc. de Biol., 1932, cix, 638.

"1 Guthmann, H., and Grars, H.: Arch. f. Gynäk., 1932, clii, 127.

s2 Chapman, A. C., and Linden, H.: Analyst, 1926, li, 563.

Bertrand, G., and Ciurea, V.: C. R. Acad. des Sci., 1931, cxcii, 780 .

s4 Davidson, L. S. P., et al.: British Medical Journal, 1933, i, 685.

Mackay, H. M. M. : Medical Research Council, Special Report Series, No. 157.

${ }^{56}$ Flanley, M. G., and Johnson, E. M.: Journ. Home Econ., 1932,

57 Neal, W. M., Becker, R. B., and Shealy, A. L.: Science, 1931, lxxiv, 418 .

soxiv, 418.
Nature, 1933 , cxxxii, 536.

Vernadsky, W.: C.R. Acad. des Sci., 1931, cxcii, 131

\section{CARCINOMA OF THE MAXILLA AND ETHMOID}

\section{A SURVEY OF THE NOTES OF FIFTY CASES}

BY

EDWARD D. D. DAVIS, F.R.C.S.

SURGEON, NOSE, THROAT, AND EAR DEPARTMENT, CHARING CROSS HOSPITAL

Carcinoma of the maxilla is fortunately comparatively rare, and statistics show that it accounts for about 1 to 2 per cent. of all malignant tumours. ${ }^{1}$ This paper is limited to a survey of fifty cases of carcinoma of the maxilla and the ethmoid seen during the past twelve years. All other tumours of the maxilla have been excluded. These cases can be divided into two definite groups.

\section{Two Groups of Cases}

The first, or lower, group consists of nine cases of squamous epithelioma arising in the alveolus or hard palate in the region of the molar teeth. The growth extends into the cheek sulcus, or may begin there, and quickly involves the cheek. Sooner or later it bursts through into the antrum and, taking the line of least resistance, fills the antrum with a soft, vascular, necrotic tumour. This squamous epithelioma may commence as the usual typical ulcer, or the growth may be deepseated and of the burrowing kind, and when it appears on the surface it has already infiltrated the cheek and antrum. The section of this deep-seated tumour was called an adenocarcinoma.

The second, or upper, group comprises forty-one cases in which the growth arose in the upper part of the nose. At the time of operation it is so extensive and necrotic that it is almost impossible to say where it originally started. There was definite evidence in fifteen of these cases to show that it originated in the floor of the orbit around the infra-orbital canal. In ten patients it began in the ethmoid and spread to the floor of the orbit. In the remaining sixteen the origin of the growth was doubtful. However, in all these it filled the antrum, being attached to the orbital periosteum and having spread into the ethmoid, even to the anterior fossa of the skull and to the other nasal sinuses.

The sections have been described as those of squamous carcinoma, adenocarcinoma, columnar-celled carcinoma, pleomorphic carcinoma. One or two were first called sarcoma, and then changed to squamous carcinoma. There were two endotheliomata arising from the middle turbinal. The sections sometimes revealed variation in the same tumour. The adenocarcinomata were those which arose near the infra-orbital canal. Though pathologists agree that these growths are undoubtedly carcinomata, there is considerable diversity in the nomenclature adopted for the type. Pathologists vary as to the Christian name, so to speak, which they give to a particular carcinoma. As would be expected, French pathologists have a different nomenclature from the British, and between most countries this variation exists. However, to the surgeon and to the clinician the pathology was the same-a rapidly growing malignant epithelial tumour, more malignant than the lower group commencing in the alveolus. The two endotheliomata were definitely. less malignant than the true carcinomata. It may be possible to apply Broders's classification of malignancy to these carcinomata. It would be of greater importance to know which types are more radio-sensitive than others.

The first, or lower, group were more commonly seen at a dental hospital or in a general surgical clinic. The second, or upper, group came to the nose and throat clinic or were sent to that clinic from an ophthalmic hospital, so that the difference in the numbers of the two groups is relatively of no importance. There were twentyseven males and twenty-three females; the ages were from 45 to 70 . The younger the patient the more malignant the growth. The patients' surroundings and occupations showed a very wide variation, and the cause of the tumour was as unknown as that of cancer. There was no history of previous disease, and no suppuration of the nose, and there was nothing which could be called precancerous.

\section{SigNS AND SYMPTOMS}

Early diagnosis is of the utmost importance. This should not be difficult in the first, or lower, group of cases ; but in spite of this nearly all these came too late for successful extirpation. There was the typical epitheliomatous ulcer, or the deformity of the alveolus and palate with painful or loose teeth. It was rarely necessary to remove a piece for section before operation. If a piece is removed the wound should be sealed by the diathermy button to prevent sepsis or a flare. The early diagnosis of the upper, or second, group of cases is well-nigh impossible, because cancer in itself does not produce any specific symptoms or signs, and it is only when the cancer cells form a tumour that a series of mechanical results appear. Furthermore, the development of these is slow and insidious, particularly in a hidden cavity like the nose, and a patient often only consults a doctor when such symptoms are well marked-frequently too late for successful removal. The general signs, such as blood changes, were of no practical value in the diagnosis. 
The most frequent first symptom is a persistent pain in the cheek, radiating to the forehead or temporal region, and accompanied by a blood-stained discharge from one nostril in a patient of cancer age. $X$-ray photographs should be taken when there is unexplained pain in the distribution of the infra-orbital nerve, and may perhaps lead to an earlier diagnosis. Chronic sinus suppuration accompanied by severe pain, which persists after the sinuses have been drained by operation, demands a search for a tumour. The teeth are frequently blamed for the pain and are extracted. Severe epistaxis in an elderly patient, not arising from the usual causes, with pain in the cheek, should raise suspicion of a growth. In this series of cases the average duration of such symptoms before the patient was seen was three months. An examination of such a case revealed a vascular, polypoid-looking swelling in the middle of the meatus of the nose, which bled freely when probed. Transillumination showed a dark antrum, and an $x$-ray photograph demonstrated a still more marked opacity of that region. The improved $x$-ray technique now adopted for the nasal sinuses produces photographs which give such valuable information as to the extent of the growth that it is essential that these photographs should be carefully studied before operation. If there is any doubt as to the presence of a tumour after such signs, exploration of the antrum through the canine fossa, with preparations for a more extensive operation, is advisable. Later symptoms were proptosis, lachrymal obstruction, and expansion of the walls of the antrum, and finally (too late) a puffy swelling of the cheek below the infra-orbital margin, where the neoplasm had burst through the wall of the antrum. Secondary growths did not occur except in two or three of the advanced and inoperable cases, when the upper deep cervical glands near the base of the skull were involved.

\section{RESUlTS OF OPERATION}

All the nine patients in the first, or lower, group were submitted to operation. One case was found to be inoperable, and a complete destruction of the tumour with diathermy or electro-surgery was impossible. There was recurrence of the neoplasm within twelve months. It was considered that a complete destruction of the growth by diathermy had been obtained in the remaining eight cases, but a recurrence appeared in five at the end of twelve months, and in three at the end of two years. Radium was implanted in three instances, with no beneficial result. The growth was well established in all these cases when first seen, but better results should have been obtained by operation and electro-surgery.

Of the forty-one cases of the upper, or second, group seven were obviously inoperable when first seen; the cheek was infiltrated and the orbit extensively invaded. These seven patients died in an average of three months after their first visit and six months from the apparent onset of symptoms. Radium was implanted in two of these with no beneficial result ; in fact, one patient died of meningitis six days after the implantation of $20 \mathrm{mg}$. of radium, but the post-mortem showed that the tumour had burst through the roof of the ethmoid into the skull. Six patients only, out of the thirty-four, were free from recurrence for more than two years. Two of these had endotheliomata and survived four and a half and five years respectively. Ohngren's results are decidedly better. Thirty-eight cases of carcinoma out of 104 were free from recurrence after two years.

\section{Operative Procedure}

The operations $I$ carried out have had the following underlying principles: (1) a thorough exposure of the neoplasm to ascertain its limits, as far as possible; and
(2) complete excision, followed by diathermy: the orthodox anatomical operation of excision of the upper jaw was discarded. The teeth are put in order as soon as possible after the patient is first seen, and as half of the hard palate is to be removed a denture or obturator of soft velum rubber is made and inserted immediately after the completion of the operation. The most satisfactory form of anaesthesia is the intratracheal, and was employed without any disadvantage. The external carotid artery was ligatured in two instances only, because it was considered that ligature did not diminish the haemorrhage. On the other hand, Ohngren has proved to his satisfaction that secondary haemorrhage after diathermy was materially diminished by ligature of the external carotid. He also advises that the ligature should be applied above the superior thyroid artery, because the clot has been known to be detached and carried into the internal carotid. Ligature is of more value when diathermy is applied to the fauces and soft. palate.

The first, or lower, group of cases were attacked by dividing the upper lip in the mid-line and carrying the incision into the nostril, the cheek then being reflected upwards so as thoroughly to expose the alveolus. The neoplasm is excised with a free margin of healthy tissue with the diathermy knife. The floor of the antrum and a large area of the hard palate are removed, the cheek is carefully examined, and any growth is widely removed by diathermy.

In the second, or upper, group of cases permission should be obtained to enucleate the eyeball if a more thorough clearance of the orbit is likely to be required, but the orbital periosteum protects the contents of the orbit. The modified Ferguson incision is made from the fronto-nasal suture down the side of the nose, around the nostril, and through the upper lip. This incision can be made with the diathermy needle, which has the advantage of diminishing the haemorrhage. The cheek is reflected upwards and outwards to the malar bone, the infraorbital margin is defined, and the whole bony wall of the side of the nose and antrum is removed. The tumour, with the floor of the orbit, is peeled off the orbital periosteum. The ethmoid infiltrated by the growth is coagulated by the diathermy button, and removed up to the base of the skull and as far back as the sphenoid.

Diathermy arrests the haemorrhage, and is applied whenever practicable and to any areas where growth is suspected. The hard palate and floor of the nose is not infiltrated by the tumour, but they should be removed to form a window, so that its area can be inspected and diathermy and radium applied after the skin incision has been closed. The details of the technique of the operation have evolved and have been improved in the later cases, when more experience had been gained. All the patients made an uneventful recovery, and not one died from the immediate or remote effects of the operation. Meningitis and injury to the eyeball was expected, but particular care was taken in dealing with the tumour in these areas. The contents of the orbit can be protected by a thin spatula insulated by a covering of rubber or vulcanite. Ohngren, who has operated on a large number of these cases with diathermy, has seen meningitis, cerebral oedema, and cerebral abscess occur with and without radium application. The application of diathermy to the orbital periosteum, and also radium exposure, has been followed by necrosis of the eyeball. In three of the above cases blindness from optic atrophy appeared with the recurrence of the growth. After diathermy, patients frequently complain of the offensive odour, in spite of irrigation with eusol. Ohngren has painted the charred area with a 2 per cent. permanganate solution and irrigated it with a 1 in 2,000 permanganate solution with success. 
The results of radium therapy up to the present has been disappointing. Deep $x$-ray exposure and teleradium - that is, exposure to the radium bomb-has been tried before operation, but the lowered state of nutrition, the risk of the increased sepsis, and the fact that the inflammatory reaction after radiotherapy delays operation counteract any possible beneficial result of such exposures. Treatment with radium immediately after operation delays healing, and the severe sepsis which follows makes the patient desperately ill. The implantation of radium is unsatisfactory, and has increased the pain and discomfort. The surface application of radium-that is, radium in small doses fixed to the upper surface of the dental obturator and applied for a prolonged period some weeks after diathermy-may produce better results. The combination of electro-surgery and $x$-ray and radiotherapy is now advocated. A free access to the growth is of course essential.

It is generally found at the operation that the tumour is more extensive than anticipated; on the other hand, cases which appear to be hopeless often do better than expected. The difficulty of early diagnosis and the inaccessibility of ethmoidal carcinoma make it doubtful whether such a mutilating operation is worth while. Nevertheless, the number of successful cases seen in Professor Holmgren's Clinic at Stockholm is encouraging. Operation relieves the patient of pain, and he has the satisfaction of knowing that determined effort has been made to rid him of the disease with a hope of success. The condition of the inoperable patient is truly a miserable one.

'Ohngren, L. G.: Acta Olo-laryngoligica, Supplementum XIX.

\section{THE LABORATORY DIAGNOSIS OF ENTERIC 'INFECTION WITH REMARKS ON THE PERSISTENCE OF INFECTION \\ BY}

A. W. DOWNIE, M.D.

LECTURER -IN BACTERIOLOGY, UNIVERSITY OF MANCHESTER

$$
\text { AND }
$$

R. W. FAIRBROTHER, M.D., M.R.C.P.

LECTCRFR IN BACTERIOLOSY AND ASSISTANT DIRECTOR OF THE PUBLIC HEALTH LABORATORY, UNIVERSITY OF MANCHESTER

Although the incidence of enteric infection in this country has greatly diminished during the present century, the continued occurrence of small outbreaks of sporadic cases indicates the endemic nature of this disease. The reason for such persistence of infection is largely the presence of carriers or undiagnosed cases in the community, as demonstrated in an unfortunate manner by the recent outbreak at Malton (Shaw, 1933). A recently published study of enteric carriers in Glasgow (Browning et al., 1933) gives details of individuals who were excreting bacteria of the enteric group over a period of years. As the ultimate source of infection must always be the discharges of human beings harbouring the particular organisms it is certain that unrecognized carriers are responsible for many of the sporadic cases of the disease.

It is thus obvious that control of enteric infection in a community depends largely on early diagnosis of cases, examination of contacts, and repeated examination of convalescents until they can be pronounced free from infection. The following report illustrates the necessity for this measure, and deals with the laboratory examination of specimens from cases in the north-west of England. Only cases which have been proved by the isolation of the infecting organisms have been considered. Cases in which diagnosis was by agglutination tests have been omitted.

\section{Material Reviewed}

During the last three years the following organisms have been isolated from individual cases under examination:

$\begin{array}{lllllrl}\text { B. } \begin{array}{l}\text { typhosum } \\ \text { B. paratyphosum }\end{array} \text { A } & \ldots & \ldots & \ldots & 25 \text { cases } \\ \text { B. paratyphosum } & \text { B } & \ldots & \ldots & \ldots & 1 \text { case } \\ \text { B. enteritidis } & \ldots & \ldots & \ldots & \ldots & \mathbf{4 8} \text { cases } \\ \text { B. aertrycke } & \ldots & \ldots & \ldots & \ldots & \mathbf{6} \text { cases } \\ \end{array}$

The last two crganisms were associated with food poisoning, except in two cases of prolonged fever from which $B$. enteritidis was isolated by blood culture. These bacteria are not considered further in this paper. The typhoid and paratyphoid infections occurred in twentyseven municipalities; their sporadic distribution indicates the endemic nature of the diseases.

Cultures were isolated from the blood, faeces, or urine, but only certain of the results of the faeces and urine are considered in detail. These serve to illustrate the persistence of infection after the febrile period.

\section{Blood Examination}

1. Culture.-In all cases where blood was received for serological examination the serum for agglutination tests was removed from the clot, which was then placed in a tube containing $10 \mathrm{c} . \mathrm{cm}$. of MacConkey's double strength bile-salt-lactose-peptone-water medium. After twentyfour and forty-eight hours' incubation at $37^{\circ} \mathrm{C}$. subcultures were made from this medium on plates of MacConkey's agar or tubes of Russell's double sugar medium. By this technique the infecting organism was frequently recovered in pure culture. Table I shows the number of positive results obtained, and the stage of the disease at which the examination was made.

TABLE I

\begin{tabular}{lrr|c|c|c}
\hline \multicolumn{2}{c|}{ Organism } & $\begin{array}{c}\text { No. of Cases } \\
\text { Examined }\end{array}$ & No. Positive & Day of Illness \\
\hline B. typhosum & $\ldots$ & $\ldots$ & 20 & 11 & $\begin{array}{l}\text { 7th-8th } \\
\text { 5th-1cth }\end{array}$ \\
B. paratyphosum B & $\ldots$ & 24 & 6 & \\
\hline
\end{tabular}

The proportion of positive blood cultures corresponds very closely to that obtained by Smith (1932), using a similar technique.

2. Agglutination Tests. - In the early stage of enteric infection examination of the faeces and urine frequently gives negative results. More useful information can usually be obtained at this time by the examination of the blood, first, by cultural examination for the presence of the infecting organism, and, secondly, for the presence of agglutinins in the serum. Cultural examination of the blood has already been mentioned, and in the typhoid cases, as shown in Table I, it proved particularly useful. Specimens of blood were not received from all the proved case 3 in this series, but in those examined the agglutination test gave definite evidence of infection. Since the method of qualitative receptor analysis was introduced by Weil and Felix (1920), the value of the method has received ample confirmation. Our routine procedure has been to combine the qualitative and the quantitative methods by testing dilutions of the serum from 1 in 20 to 1 in 2,560 with both " $\mathrm{H}$ " and " $\mathrm{O}$ " suspensions of various organisms of the enteric group. The suspensions used were obtained from the Standards Laboratory, Oxford. In Tables II and III, however, only the results with the suspensions of $B$. typhosum and $B$. paratyphosum $\mathrm{B}$ have been given. In all cases the infecting organism was isolated from the blood, faeces, or urine. 